\title{
Maailmankaupan vapautumisen vaikutukset maataloudelle
}

\author{
Jyrki Niemi1), Leena Kerkelä2) ja Heikki Lehtonen1), \\ 1)MTT Taloustutkimus,_Luutnantintie 13,00410Helsinki,jyrki.niemi@mtt.fi,heikki.lehtonen@mtt.fi \\ 2)Valtion taloudellinen tutkimuskeskus VATT, PL 1279,00531 Helsinki, leena.kerkelä@vatt.fi
}

\section{Tiivistelmä}

Maailman kauppajärjestö WTO:n käynnissä olevalla Dohan neuvottelukierroksella maataloustuotteiden kauppasäännöistä sopiminen on yksi kierroksen pääkysymyksiä. Tavoitteeksi on asetettu maataloustuotteiden vientitukien lopettaminen sekä teollisuusmaissa maksettavien maataloustukien merkittävä vähentäminen ja maataloustuotteiden tullien alentaminen. Vientitukien poistaminen koskee Euroopan unionissa (EU) ja sitä kautta myös Suomessa erityisesti maitoa, sokeria ja rehuviljaa.

Tämän tutkimuksen tavoitteena on arvioida käynnissä olevan Dohan neuvottelukierroksen aiheuttamia muutospaineita EU:n maatalous- ja elintarvikemarkkinoihin ja sitä kautta syntyviä heijastusvaikutuksia Suomen maatalous- ja elintarviketaloudelle. Keskeiset selvitettävät kysymykset ovat: 1) Mitä vaikutuksia vientituen poistamisella olisi EU-alueella ja Suomessa? 2) Miten tullien merkittävä alentaminen vaikuttaisi maataloustuotteiden markkinoihin EU:ssa ja Suomessa? Tärkeä kysymys on myös se, onko vuonna 2003 sovittu yhteisen maatalouspolitiikan (CAP) uudistus edistänyt unionin maatalouden sopeutumista liberaalimpaan kaupan ympäristöön. Tutkimuksen kvantitatiiviset tulokset on saatu hyödyntämällä globaalia taloutta kuvaavaa numeerista GTAP-tasapainomallia ja mallia tukevaa tietokantaa.

Tutkimustulosten mukaan vientituista luopuminen merkitsisi EU:ssa alempaa tuottajahintatasoa ja sen seurauksena tuotannon supistumista ja viennin vähentymistä. Vientitukien poistuminen vaikuttaisi EU:ssa eniten rehuviljan tuotantoon. Suomessa vientitukien poistosta aiheutuva viennin väheneminen olisi haasteellisinta rehuviljan ja maidon tuotannolle. Mallilaskelmien mukaan rehuviljan tuotanto alenisi Suomessa pitkällä aikavälillä noin 14 prosenttia ja maidontuotanto lähes seitsemän prosenttia.

Vientitukien poistamisen ja tuontitullien alentamisen yhteisvaikutuksia EU:n ja Suomen maatalousmarkkinoihin on arvioitu tutkimuksessa kahden vaihtoehtoisen skenaarion pohjalta: (1) EU:n ehdotus, jonka mukaan korkeimpia tulleja alennettaisiin 60 prosenttia ja muita tulleja $25-60$ prosenttia ja (2) USA:n ehdotus, joka leikkaisi korkeimpia tulleja peräti 90 prosenttia. Tuontitullien alentamisen seurauksena EU:n tuotanto ja vienti supistuisivat lähes kaikkien maataloushyödykkeiden kohdalla. Voimakkainta tuotannon väheneminen olisi sokerissa ja naudanlihatuotteissa. Simulointitulosten perusteella USA:n ehdotuksen toteutuminen vähentäisi sokerin ja naudanlihan tuotantoa unionissa yli 20 prosenttia. Maitotaloustuotteiden tuotanto alentuisi EU:ssa vajaat 12 prosenttia. Suomessa sokerin, rehuviljan ja muun kasvinviljelytuotannon volyymi alenisi tulosten mukaan yli 15 prosenttia USA:n ehdotuksen toteutuessa. Maidontuotannon volyymi alentuisi noin 13 prosenttia.

Maatalouskaupan vapauttaminen johtaisi tutkimustulosten mukaan myös maataloustuotteiden maailmankaupan merkittävään alueelliseen uusjakoon. EU:n menettämistä maailmanmarkkinoista suurimman osan saisivat USA, Australia, Uusi-Seelanti ja MERCOSUR-maat.

Asiasanat: WTO, EU, vientituki, tuontitulli, kaupan vapautuminen 


\section{Johdanto}

Maailman kauppajärjestön (WTO) neuvottelut maataloustuotteiden kaupan vapauttamiseksi alkoivat jo vuoden 2000 alkupuolella Uruguayn neuvottelukierroksen maataloussopimuksen (URAA) artikkelin 20 perusteella. Dohan ministeritason kokouksessa vuoden 2001 marraskuussa täsmennettiin maatalousneuvottelujen tavoitteita, jatkettiin aiemmin käynnistettyä työtä sekä asetettiin aikarajoja. Maataloustuotteiden kaupan osalta Dohan kierroksen päätavoitteiksi sovittiin "markkinoillepääsyn huomattava edistäminen; kaikenlaisten vientitukien vähentäminen ja lopulta niiden poistaminen; ja kaupankäyntiä vääristävän kotimaisen tuen huomattava vähentäminen."

Dohan kierroksen lopputuloksella odotetaan olevan merkittävä vaikutus EU:n ja Suomen maaja elintarviketalouteen. Vientituista luopumisen ja tuontisuojan madaltumisen on arvioitu laskevan maataloustuotteiden tuottajahintoja EU-markkinoilla. Uuden sopimuksen mahdollisista seurauksia on ehditty arvioida jo lukuisissa tutkimuksissa, kuten Anderson ja Martin (2006); Bouet, Mevel ja Orden (2005), Decreux ja Fontagné (2006), Fontagne et al. (2005); ja Jensen ja Yu (2006). Tutkimusten tuottamat tulokset eroavat jonkin verran toisistaan heijastaen muun muassa erilaisia menetelmävalintoja sekä tehtyjä alkuoletuksia.

Tässä tutkimuksessa tarkastellaan käynnissä olevan kauppaneuvottelukierroksen aiheuttamia muutospaineita EU:n maatalous- ja elintarvikemarkkinoihin ja sitä kautta syntyviä heijastusvaikutuksia Suomen maatalous- ja elintarviketaloudelle. Keskeiset selvitettävät kysymykset ovat: 1) Mitä vaikutuksia vientituen poistamisella olisi EU-alueella ja Suomessa? 2) Miten tullien merkittävä alentaminen vaikuttaisi maataloustuotteiden markkinoihin EU:ssa ja Suomessa?

Tärkeä kysymys tässä yhteydessä on myös se, onko vuonna 2003 sovittu yhteisen maatalouspolitiikan (CAP) uudistus edistänyt unionin maatalouden sopeutumista liberaalimpaan kaupan ympäristöön. Vaikka CAP-uudistus ei suoranaisesti koskenut maatalouden kauppapolitiikkaa, vientitukien vähentyminen ja tuontisuojatarpeen madaltuminen ovat uudistuksen epäsuoria vaikutuksia. Erityisesti peltokasvi- ja kotieläintukien irrottamisen tuotannosta oletetaan parantavan EU:n kykyä sopeutua liberaalimpiin maatalousmarkkinoihin, jotka ovat väistämättä edessä.

Tutkimuksessa hyödynnetään globaalia taloutta kuvaavaa numeerista tasapainomallia ja mallia tukevaa tietokantaa (GTAP), joita on maailmalla sovellettu laajalti erilaisten kansainvälistä kauppaa koskevien kysymysten tarkasteluun. GTAP-mallin tulokset tarjoavat arvioita politiikkamuutosten vaikutuksista kauppavirtoihin sekä globaalilla että EU:n tasolla. Tässä tutkimuksessa keskitytään erityisesti globaalien kauppapäätösten EU-tason ja kansallisen tason vaikutuksiin.

Tutkimus on jaettu neljään lukuun. Johdantoluvun jälkeen tutkimuksen toisessa luvussa perehdytään tutkimusmenetelmään ja -aineistoon. Kolmannessa luvussa esitellään tutkimustulokset ja neljännessä luvussa tuloksista tehdyt johtopäätökset.

\section{Aineisto ja menetelmä}

Tutkimuksessa hyödynnetään globaalia taloutta kuvaavaa numeerista tasapainomallia ja mallia tukevaa tietokantaa (GTAP), joita on maailmalla sovellettu laajalti erilaisten kansainvälistä kauppaa koskevien kysymysten tarkasteluun. Komparatiivis-staattisella GTAP-mallilla suoritetaan 'mitä jos' kysymyksenasetteluun perustuvia politiikka-arvioita. Standardi GTAP-malli (Hertel ja Tsigas 1997) on staattinen, tuotantoteknologialtaan vakioskaalatuottoinen ja markkinarakenteeltaan täydellisen kilpailun tasapainomalli. Mallin tulokset perustuvat oletukseen yritysten ja kuluttajien optimaalisesta käyttäytymisestä, jota rajoittavat käytettävissä olevat resurssit (maa, työvoima, pääoma, luonnonvarat), erilaiset rajoitukset (verot jne.) ja niiden funktiot. Mallin tasapainoratkaisussa markkinat ovat tasapainossa (eli kysyntä ja tarjonta ovat yhtä suuria).

GTAP-tietokanta sisältää 87 alueen tai maan panos-tuotos -pohjaisen toimialakuvauksen. Aluetaloudet on jaettu mallissa 57 toimialaan, joista noin puolet on teollisuustoimialoja ja loput alkutuotantoa, rakentamista ja palveluita. Alueiden välisiä linkkejä kuvataan mallissa toimialojen välisillä bilateraalisilla kauppavirroilla. Tuontihyödykkeet oletetaan epätäydellisiksi substituuteiksi kotimaisten vastaavien hyödykkeiden kanssa. Tämä mahdollistaa ristikkäiskaupan huomioimisen.

Toimialaluokituksensa puolesta GTAP-mallin tietokanta soveltuu hyvin WTO-neuvottelujen maatalouskysymysten arviointiin, koska maataloustuotteet ovat siinä hyvin edustettuina. Toimialaluokituksessa on mukana 12 maataloustoimialaa sekä 8 elintarvikkeita jalostavaa sektoria.

Kauppapolitiikka on mallitettu GTAP-tietokannassa ja mallin hintayhtälöissä ad valorem-tukina tai veroina. Maatalouden osalta tukien laskemisessa on hyödynnetty OECD:n PSE-aineistoa siten, että 
rajasuoja on erotettu omaksi komponentikseen ja muu tuki on laskettu residuaalina ja määritelty tuotetukipalkkioina. Tukimaksut on jaettu neljään kategoriaan: tuotantotuet, väliportaan tuotantopanosten tuet, tilakohtaiset tuet ja pääomatuet.

Tutkimuksessa käytettävän GTAP-mallin tietokanta perustuu vuoden 2001 maailmantaloutta kuvaavaan aineistoon (Versio 6.0). Mallin perusversiota laajennettiin tutkimuksessa sisällyttämällä siihen EU:n yhteisen maatalouspolitiikan uudistuksen vaikutukset, jota varten selvitettiin maakohtaisesti hallitusten tekemät valinnat vuonna 2003 päätetyssä ja vuosina 2005-2006 toimeenpannussa CAP-uudistuksessa. Lähtöaineistoina käytettiin Euroopan komission tiedottamia valintoja eri maiden CAP-uudistusvalinnoista (Euroopan kommissio 2004a,b, 2005). Kun makohtaiset valinnat painotettiin maiden eläinmäärillä, saatiin CAP-nautatukien irrotuksen aste käyttämällämme aluejaolla GTAPmallissa. Lopputuloksena saatiin huomattavia eroja tuotantosidonnaisissa CAP-nautatuissa eri alueiden kesken. Esimerkiksi Saksassa, Alankomaissa, Britanniassa ja Irlannissa kaikki CAP-tuki irrotettiin tuotannosta, kun taas Ranskassa peräti $63 \%$ nautatuista jäi tuotantosidonnaiseksi. Suomessa vastaava osuus on noin $50 \%$. Kaikista CAP-tuista tuotantosidonnaiseksi jäi EU:ssa keskimäärin alle $10 \%$ kuten Suomessakin, koska peltotuet ja maitopalkkio irrotettiin tuotannosta.

CAP-uudistuksen mallintamisessa hyödynnettiin kansainvälisiä esimerkkejä huomioiden tilatuen merkitys lähinnä yleisenä maan tukena (Bach et al, 2000; Frandsen et al. 2002; Brockmeier et al., 2006; Jensen (2006), Jensen ja Yu (2006). Uudistuksessa määriteltyjen tukipalkkioiden perusteella laskettiin tuotannosta irrotettuun tilatukeen menevä osuus CAP-tuesta ja jäljelle jäävä tuotantosidonnainen CAP-tuki eri nautaeläimille. Tämä mallilaajennus mahdollistaa maatalouspolitiikan uudistuksen vaikutusten simuloinnit eri tuotantosuunnissa.

CGE -malleissa kuten GTAP kunkin tuotteen tuotantofunktiossa on määritelty panokset ja niiden välinen substituutio eli korvautuvuus. Kunkin mallin rakenteesta riippuu, mitä panoksia, kuten, maa-ala, työvoima, pääoma ja välituotteet, käytetään minkin tuotteen tuotannossa ja miten ne voivat korvata toisiaan. Tältä pohjalta voidaan määritellä miten maataloustuet vaikuttavat tuotantoon kunkin panoksen kautta ja kuinka maatalouspolitiikan muutokset muuttavat tukien vaikutuksia tuotantoon. Tukien jakaminen eri panosten kesken ei ole aina täysin yksikäsitteistä koska itse panoksetkin ovat voimakkaasti aggrekoituja abstraktioita. Esimerkiksi Gohin (2006) ja Jensen \& Yu (2005) ovat nähneet aiheelliseksi käsitellä CAP-sonnipalkkiot suoraan tuotokselle eli naudanlihalle maksettavina tukina (koska sonnien teuraspaino ja ruokinta vastaa suhteellisen suoraan panosten ja lihan hinnan muutoksiin), kun taas emolehmäpalkkiot ja hiehoille maksettavat teurastustuet käsiteltiin pääomakannan tukena. Näistä valinnoista, joita olemme noudattaneet myös tässä tutkimuksessa, seuraa, että sonnipalkkiolla on suorempi vaikutus naudanlihantuotantoon kuin emolehmä- ja teurastuspalkkiolla, joilla puolestaan on suurempia vaikutuksia naudanlihantuotantoon kuin esimerkiksi peltoalatuilla. Näiden vaikutusten keskinäinen suuruus riippuu käytetystä tuotantofunktion muodosta ja mallin kalibroinnissa määritetyistä substituutiojoustoista panosten välillä.

Koska 2003 päätetty CAP -reformi tarkoittaa merkittävän osan CAP-nautapalkkioiden muuttumista pinta-alaperusteisiksi, reformi nostaa pellon arvoa ja vähentää naudanlihantuotannosta saatavia tuottoja. Samalla tavalla CAP-peltokasvituen irrottaminen viljan ja öljykasvien aloista ja maksaminen kaikelle hoidetulle pellolle vähentää kannustinta viljan ja öljykasvien tuotantoon, mutta toisaalta lisää kannustinta kaikkien niiden kasvien tuotantoon, jotka eivät aiemmin ole CAP-peltokasvitukea saaneet. Tällaisia kasveja ovat esimerkiksi nurmikasvit. Tässä kokonaisuudessa CAP-uudistuksen vaikutus esimerkiksi naudanlihan tuotantoon riippuu 1) panosten välisestä substituutiosta naudanlihan tuotantofunktiossa, 2) naudanlihantuotannossa tarvittavien rehujen tuotantomuutoksista niiden panosten substituutiosuhteiden perusteella, sekä 3) naudanlihan korvautuvuudesta muilla lihoilla ja elintarviketuotteilla kuluttajan hyötyfunktiossa, tähän vaikuttaa olennaisesti myös se, kuinka halvalla naudanlihaa voidaan tuoda muualta maailmasta kuten Brasiliasta kauppapolitiikan eri vaihtoehdoilla. Tästä tuki- ja kauppapolitiikan kokonaisuudesta siis riippuu, millä hinnalla naudanlihaa tuotetaan, kulutetaan ja tuodaan EU:n sisämarkkinoille ja mihin esim. suomalaisen naudanlihan tasapainohinta asettuu. Tähän vaikuttaa edelleen se, kuinka paljon kuluttajat pitävät kotimaista lihaa erilaisena tuotteena kuin tuontilihaa. Muiden tuotteiden kohdalla tasapainohinnat, tuotanto ja kauppavirrat määräytyvät samanaikaisesti vastaavanlaisen logiikan ja vuorovaikutussuhteiden seurauksena.

EU-tullitaso määriteltiin malliin niin, että se paremmin huomioisi tuontikysynnän kasvun tapauksissa, joissa nykyinen kauppapolitiikka on rajoittanut tuontia merkittävästi tai lähes kokonaan. Tässä yhteydessä myös Itä- ja Keski-Euroopan maiden kauppapolitiikka yhtenäistettiin EU-politiikan kanssa 
ja sen perusteella laskettiin EU-tasolla yhtenäinen tullitaso eri tuoteryhmille. Laskelmien tuloksena saatiin eri tullinalennusskenaarioihin liittyvät tuotekohtaiset tullien alenemiset, jotka ovat monissa tapauksissa suurempia kuin aiemmin tehdyissä tutkimuksissa.

Taulukko 1. Malli alueiden ja hyödykkeiden jaottelusta (GTAP Version 6)

\begin{tabular}{|c|c|c|c|}
\hline Alueet & Lyhenteet & Sektorit & Lyhenteet \\
\hline$\overline{E U}-15$ & EU & Vehnä & WHEAT \\
\hline \multicolumn{2}{|c|}{ Muut EU:hun hyv.maat, KroatiaREU } & Muut viljat & GRO \\
\hline Sveitsi, Norja, Islanti & EFT & Vihannekset, hedelmät & V_F \\
\hline USA & USA & Muut viljelykasvit & OCER \\
\hline \multicolumn{4}{|l|}{ Etelä-Amerikan talousalue } \\
\hline Australia ja Uusi-Seelanti & AUSNZ & Eläintuotteet & OTAG \\
\hline Venäjä & RUSSIA & Naudanliha & CATTMEAT \\
\hline Kiina ja Hongkong & CHINA & Muut lihatuotteet & OTMEAT \\
\hline $\begin{array}{l}\text { Intia } \\
\text { Vähiten kehittyneimmät }\end{array}$ & INDIA & Meijerituotteet & DAIRY \\
\hline $\begin{array}{l}\text { Văhiten kehittyneimmăt } \\
\text { Afrikan maat }\end{array}$ & LDCs & Sokeri & SUGAR \\
\hline Muu maailma & ROW & $\begin{array}{l}\text { Muut elintarvikkeet } \\
\text { Voimavarat } \\
\text { Valmistus } \\
\text { Palvelut }\end{array}$ & $\begin{array}{l}\text { OTFOOD } \\
\text { RESOUR } \\
\text { MANUFAC } \\
\text { SVCES }\end{array}$ \\
\hline \multicolumn{4}{|l|}{ Muut kokonaisuudet } \\
\hline Suomi & \multicolumn{3}{|l|}{ FIN } \\
\hline Ranska & \multicolumn{3}{|l|}{ FRA } \\
\hline Saksa ja Itävalta & \multicolumn{3}{|c|}{ GERA } \\
\hline Pohjois-EU & \multicolumn{3}{|c|}{ NEU; Alankomaat, Belgia, Britannia, Irlanti, Tanska, Ruotsi } \\
\hline Etelä-EU & \multicolumn{3}{|c|}{ SEU; Italia, Espanja, Kreikka, Portugali } \\
\hline Puola & \multicolumn{3}{|c|}{ REU } \\
\hline Muut EU:hun hyväksytyt maat & \multicolumn{3}{|l|}{ REU } \\
\hline
\end{tabular}

Lähde: GTAP tietokanta 6.0

GTAP-tietokannan 87 alueesta ja 57 toimialasta aggregoitiin tutkimuksessa mallisimulointeja varten 11 alueen ja 14 toimialan aineisto (Taulukko 1). Tarkasteluun otettiin mukaan tärkeimmät maatalouden vienti- ja tuontialueet (Australia/Uusi-Seelanti, Kiina, EU-15, Intia, MERCOSUR, Venäjä ja Yhdysvallat). Australia/Uusi-Seelanti, Etelä-Amerikan talousalue MERCOSUR ja Yhdysvallat ovat maataloustuotteiden suurimpia viejiä, kun taas Venäjä on esimerkki yksittäisestä suuresta elintarvikkeiden tuontimaasta. Aluekokonaisuus 'Muut EU-maat' sisältää kymmenen uutta EU:n jäsenmaata sekä Bulgarian, Kroatian ja Romanian. EFTA-ryhmään kuuluvat Islanti, Norja ja Sveitsi. Analyysin syventämiseksi EU on jaettu kuuteen eri alueeseen. Sen lisäksi Puola on erotettu muista Itä-Euroopan maista. Hyödykkeiden osalta suurin osa maatalous- ja elintarviketuotteista on säilytetty alkuperäisessä GTAP-tietokannassa, kun taas muut kuin maataloustuotteet on jaoteltu valmistukseen ja palveluihin.

Vientitukien poistamisen ja tuontitullien alentamisen yhteisvaikutuksia EU:n ja Suomen maatalousmarkkinoihin on arvioitu tutkimuksessa kahden vaihtoehtoisen skenaarion pohjalta: (1) EU:n ehdotus, jonka mukaan korkeimpia tulleja alennettaisiin 60 prosenttia ja muita tulleja 25-60 prosenttia ja (2) USA:n ehdotus, joka leikkaisi korkeimpia tulleja peräti 90 prosenttia.

\section{Tulokset}

Tutkimuksen tuottamat tulokset vientitukien ja tuontitullien vaikutuksista vientiin, tuontiin ja tuotantoon koko EU:ssa on esitelty taulukossa 1. Sekä EU:n että USA:n ehdotukset kaupan vapauttamiseksi johtavat tulosten mukaan siihen, että EU:n osuus maailman elintarvikekaupasta pienenee. Eniten vähenisi EU:n naudanlihan ja sokerintuotanto. EU:n ehdotuksessa molemmat vähenisivät noin $15 \%$ ja USA:n ehdotuksessa yli viidenneksen. Näissä tuoteryhmissä tuontitullien alennus olisi suhteellisesti suurinta. Asiaan vaikuttaa myös se, että suuret naudanlihan tuottajamaat EU:ssa, kuten Sak- 
sa, Britannia ja Alankomaat, ovat irrottaneet kaiken CAP-tuen tuotannosta. Näissä maissa naudanlihantuotanto vähenee jopa neljänneksen eli suhteellisesti paljon enemmän kuin esimerkiksi Ranskassa ja Suomessa jossa vähintään puolet CAP-nautapalkkioista on jätetty tuotantosidonnaisiksi.

Taulukko 2. Maatalouskaupan vapautumisen vaikutukset (\%) EU:lle skenaarioissa 1 ja 2.

\begin{tabular}{lcrrrrr}
\hline Tuote & \multicolumn{3}{c}{ Skenaario 1 } & & & Skenaario 2 \\
& Vienti & Tuonti & Tuotanto & Vienti & Tuonti & Tuotanto \\
\hline Vehnä & -18 & +8 & $-10,4$ & -18 & +9 & $-11,4$ \\
Rehuvilja & -22 & +1 & $-8,4$ & -27 & +2 & $-11,0$ \\
Sokeri & -60 & +65 & $-14,6$ & -71 & +128 & $-22,4$ \\
Naudanliha & -57 & +64 & $-15,4$ & -72 & +124 & $-22,8$ \\
Sian- ja siipikarjanliha & -5 & +7 & $-1,8$ & +1 & +16 & $-2,2$ \\
Maitotuotteet & -23 & +11 & $-7,1$ & -28 & +33 & $-11,5$ \\
Maito & & & & & & \\
\hline
\end{tabular}

Tuotannon aleneminen Länsi-Euroopassa CAP-reformin ja vientitukien poistumisen seurauksena (taulukko 3) lieventää olennaisesti tullien alentamisen aiheuttamaa hintojen laskua. Hintojen lasku jää lopulta tullien alenemisesta huolimatta suhteellisen vähäiseksi, muutamien prosenttien suuruiseksi tuotannon sopeutumisen jälkeen.

Taulukko 3. Tuotantovaikutusten (\%) dekomponointi EU:ssa skenaariossa 1.

\begin{tabular}{lcccccc}
\hline Tuote & Vehnä & Rehuvilja & Sokeri & Naudanliha & $\begin{array}{c}\text { Sika- ja } \\
\text { siipikarjanliha }\end{array}$ & Maitotuotteet \\
\hline CAP-uudistus & $-6,4$ & $-2,1$ & +0 & $-1,8$ & +0 & $-3,8$ \\
Vientitukien poisto & $-3,1$ & $-3,6$ & $-2,1$ & $-2,6$ & $-1,2$ & $-2,6$ \\
Tullien alennus & $-0,9$ & $-2,7$ & $-12,6$ & $-10,9$ & $-0,6$ & $-0,7$ \\
Yhteensä & $-10,4$ & $-8,4$ & $-14,6$ & $-15,4$ & $-1,8$ & $-7,1$ \\
\hline
\end{tabular}

Ellei tuotanto alenisi merkittävästi EU:n suurissa tuottajamaissa, EU:n hintataso laskisi enemmän ja tällöin myös tuotanto vähenisi Suomessa selvästi enemmän. Uusissa jäsenmaissa kuten Puolassa, jossa nautaeläimet eivät saa jatkossakaan tuotantosidonnaisia CAP-tukia, naudanlihantuotanto kasvaa tullien alenemisesta huolimatta.

Taulukko 4. Maatalouskaupan vapautumisen tuotantovaikutukset (\%) EU-jäsenmaissa skenaariossa 1.

\begin{tabular}{lrccccc}
\hline Tuote & Vehnä & Rehuvilja & Sokeri & Naudanliha & $\begin{array}{c}\text { Sika- ja } \\
\text { siipikarjanliha }\end{array}$ & Maitotuotteet \\
\hline Suomi & -4 & -13 & -9 & -6 & -3 & -11 \\
Ranska & -9 & -11 & -16 & -11 & -3 & -10 \\
Saksa & -14 & -12 & -8 & -22 & -3 & -6 \\
Puola & +1 & +2 & -1 & +1 & -1 & +16 \\
Pohjoinen EU & -9 & -14 & -25 & -26 & -2 & -11 \\
Eteläinen EU & -27 & -5 & -21 & -9 & -1 & -6 \\
Muu EU & +3 & +1 & -1 & +1 & +1 & +17 \\
\hline
\end{tabular}

Vaikka vehnän ja naudanlihantuotanto alenee tulosten mukaan Suomessa suhteellisesti keskimääräistä vähemmän, maidon ja rehuviljan tuotanto alenee Suomessa ja pohjoisen EU:n alueella selvästi EU:n keskiarvoa enemmän (taulukko 4).

Maatalouskaupan vapauttaminen johtaisi tutkimustulosten mukaan myös maataloustuotteiden maailmankaupan merkittävään alueelliseen uusjakoon (taulukko 5). EU:n menettämistä maailmanmarkkinoista suurimman osan saisivat USA, Australia, Uusi-Seelanti ja MERCOSUR-maat. 
Taulukko 5. Maatalouskaupan vapautumisen tuotantovaikutukset (\%) globaalisti skenaariossa 1.

\begin{tabular}{lccccrc}
\hline Tuote & Vehnä & Rehuvilja & Sokeri & Naudanliha & $\begin{array}{c}\text { Sika- ja } \\
\text { siipikarjanliha }\end{array}$ & Maitotuotteet \\
\hline EU & -10 & -8 & -15 & -15 & -2 & -7 \\
Yhdysvallat & +5 & +2 & -1 & +4 & +5 & +1 \\
Kiina & +0 & +8 & +1 & -0 & -0 & +6 \\
Intia & -0 & +0 & +0 & -2 & +204 & +2 \\
MERCOSUR & -7 & +7 & -5 & +11 & -3 & +4 \\
Australia/Uusi-Seelanti & +0 & +6 & +44 & +25 & +0 & +27 \\
Kehitysmaat & +8 & +0 & +6 & +7 & +2 & +34 \\
\hline
\end{tabular}

Myös Suomessa tuotanto ja vienti supistuisivat tarkastelluissa skenaariovaihtoehdoissa kaikilla maatalouden toimialoilla. USA:n ehdotuksen toteutuessa sokerin, rehuviljan ja muun kasvinviljelytuotannon volyymi alenisi Suomessa tulosten mukaan yli 15 prosenttia. Suomalaisen maatalouden kannalta keskeisen maidontuotannon volyymi alenisi noin 7 prosenttia ja maitotuotteiden arvo 13 prosenttia.

Taulukko 6. Maatalouskaupan vapautumisen vaikutukset (\%) Suomelle skenaarioissa 1 ja 2.

\begin{tabular}{|c|c|c|c|c|c|c|}
\hline \multirow[b]{2}{*}{ Tuote } & \multicolumn{3}{|c|}{ Skenaario 1} & \multicolumn{3}{|c|}{ Skenaario 2} \\
\hline & Vienti & Tuonti & Tuotanto & Vienti & Tuonti & Tuotanto \\
\hline Vehnä & -18 & +4 & -4 & -24 & +5 & -5 \\
\hline Rehuvilja & -31 & -7 & -14 & -34 & -3 & -16 \\
\hline Sokeri & -62 & +142 & -9 & -58 & +310 & -15 \\
\hline Naudanliha & -80 & +96 & -6 & -89 & +209 & -9 \\
\hline Sian- ja siipikarjanliha & -16 & +15 & -3 & -3 & +28 & -4 \\
\hline Maitotuotteet & -64 & +19 & -11 & -70 & +49 & -13 \\
\hline Maito & & & -6 & & & -7 \\
\hline
\end{tabular}

Taulukko 7. Tuotantovaikutusten (\%) dekomponointi Suomessa skenaariossa 1.

\begin{tabular}{|c|c|c|c|c|c|c|}
\hline Tuote & Vehnä & Rehuvilja & Sokeri & Naudanliha & $\begin{array}{c}\text { Sika- ja } \\
\text { siipikarjanliha }\end{array}$ & Maitotuotteet \\
\hline CAP-uudistus & $-1,6$ & $-0,1$ & & $-1,0$ & $-1,6$ & $-6,0$ \\
\hline Vientitukien poisto & $-0,7$ & $-12,0$ & & $-1,4$ & $-1,3$ & $-5,0$ \\
\hline Tullien alennus & $-1,6$ & $-1,8$ & & $-3,8$ & $-0,3$ & -0 \\
\hline Yhteensä & $-4,0$ & $-13,9$ & & $-6,2$ & $-3,3$ & $-10,9$ \\
\hline
\end{tabular}

\section{Johtopäätökset}

Tässä tutkimuksessa on arvioitu käynnissä olevan Dohan neuvottelukierroksen aiheuttamia muutospaineita EU:n maatalous- ja elintarvikemarkkinoihin ja sitä kautta syntyviä heijastusvaikutuksia Suomen maatalous- ja elintarviketaloudelle. Tutkimuksen kvantitatiiviset tulokset on saatu hyödyntämällä globaalia taloutta kuvaavaa numeerista GTAP-tasapainomallia ja sitä tukevaa tietokantaa.

Tulosten mukaan vientituista luopuminen merkitsisi EU:ssa alempaa tuottajahintatasoa ja sen seurauksena tuotannon supistumista ja viennin vähentymistä. Nykyiset tuotantomäärät ovat olleet vientitukien ja tuotantosidonnaisten CAP-tukien avulla kannattavia, mutta vientitukien poistuessa EU:n ylituotantoa ryhdyttäisiin vähentämään ja kauppaamaan unionin sisällä ja siten kilpailu sisämarkkinoilla kiristyisi, tuotteiden hinta alenisi ja tuotanto vähenisi. Vientitukien poistuminen vaikuttaisi EU:ssa eniten rehuviljan tuotantoon. Suomessa vientitukien poistosta aiheutuva viennin väheneminen olisi haasteellisinta rehuviljan ja maidon tuotannolle.

Vientitukien poistamisen ja tuontitullien alentamisen yhteisvaikutuksia EU:n ja Suomen maatalousmarkkinoihin on arvioitu tutkimuksessa kahden vaihtoehtoisen skenaarion pohjalta: (1) EU:n ehdotus, jonka mukaan korkeimpia tulleja alennettaisiin 60 prosenttia ja muita tulleja 25-60 prosenttia ja 
(2) USA:n ehdotus, joka leikkaisi korkeimpia tulleja peräti 90 prosenttia. Esitettyjen tullinalennusskenaarioiden toteutuminen merkitsisi EU:n tuotannon ja viennin supistumista lähes kaikkien maataloushyödykkeiden kohdalla. Voimakkainta tuotannon supistuminen olisi sokerissa ja naudanlihassa. Simulointitulosten perusteella USA:n ehdotuksen toteutuminen vähentäisi sokerin ja naudanlihan tuotantoa unionissa yli 20 prosenttia. Maitotaloustuotteiden tuotanto alentuisi EU:ssa vajaat 12 prosenttia. Myös Suomessa tuotanto ja vienti supistuisivat tarkastelluissa skenaariovaihtoehdoissa kaikilla maatalouden toimialoilla.

Maatalouskaupan vapauttaminen johtaisi tutkimustulosten mukaan myös maataloustuotteiden maailmankaupan merkittävään alueelliseen uusjakoon. EU:n menettämistä maailmanmarkkinoista suurimman osan saisivat USA, Australia, Uusi-Seelanti ja MERCOSUR-maat.

\section{Kirjallisuus}

Anderson, K.\& Martin, W. 2006. Agricultural Trade Reform and Doha Development Agenda. Palgrave McMillan, co-published by World Bank. http:/publications.worldbank.org/ecommerce/catalog

Bach C.F., Frandsen S.E. and Jensen H.G. 2000. Agricultural and Economy-Wide Effects of European Enlargement: Modelling the Common Agricultural Policy. Journal of Agricultural Economics, 51(2): 162-180.

Bouët A., Mevel S., and D. Orden, 2006. 'More or less ambition in the Doha Round? Modeling the development impact of trade proposals', A paper presented at the $9^{\text {th }}$ Annual Conference on Global Economic Analysis, Addis Abebe, Ethiopia.

Brockmeier, M., Klepper, R. \& Pelikan, J. 2006. A Comparison of the Most Recent Proposals for Market Access. A paper presented at the ENARPRI Conference, June 8, 2006, Brussels, Belgium. Available at http://www.enarpri.org/Publications/ConNo3.pdf

Decreux, Y. \& Fontagné, L. 2006. Quantitative Assessment of the Outcome of the Doha Development Agenda. CEPII, Woorking paper No 2006-10. 50p. http://www.cepii.fr/anglaisgraph/workpap/summaries/2006/

European Commission 2004a. Commission Regulation (EC) No 796/2004 of 21 April 2004. http://eur-lex.europa.eu/LexUriServ/site/en/consleg/2004/R/02004R0796-20050325-en.pdf

European Commission 2004b. Commission Regulation (EC) No 795/2004 of 21 April 2004 http://eur-lex.europa.eu/LexUriServ/site/en/consleg/2004/R/02004R0795-20050101-en.pdf

European Commission 2005. Commission Regulation (EC) No 118/2005 of 26 January 2005 http://eur-lex.europa.eu/LexUriServ/site/en/consleg/2005/R/02005R0118-20050416-en.pdf

Fontagne L., Guerin J.-L. and S. Jean, 2005. Market access liberalization in the Doha Round: scenarios and assessment, The World Economy, 28, 8, 1073-1094.

Frandsen, S., Gersfeld, B., \& Jensen, H. 2002. Decoupling Support in Agriculture: Impacts of redesigning European Agricultural Support. Paper presented at the $5^{\text {th }}$ Annual Conference on Global Economics Analysis, Taipei. Available at http://www.gtap.agecon.purdue.edu/resources

Gohin A. 2006. Assessing CAP Reform: Sensitivity of Modelling Decoupled Policies. Journal of Agricultural Economics, 57(3), 415-440.

Hertel, T. and Tsigas, M. 1997. "Structure of GTAP", in Hertel, Thomas (ed.) Global Trade Analysis, Cambridge University Press.

Jensen, H.G. 2006. V6 Documentation - Chapter 16.C: Domestic Support: European Union. https://www.gtap.agecon.purdue.edu/resources/res_display.asp?RecordID $=1822$

Jensen, H. \& Yu, Wusheng 2006. Reforming Agricultural Domestic Support of the EU in the Doha Round: Measurement, Feasibility, and Consequences A paper presented at the ENARPRI Conference, June 8, 2006, Brussels, Belgium. Available at http://www.enarpri.org/Publications/ConNo3.pdf 